\title{
Chronic Cough in Thymoma
}

\author{
Agrawaal KK, ${ }^{1}$ Dhakal SS, 'Bhatta N, ${ }^{1}$ Pradhan B, ${ }^{1}$ Chaurasia RK, ${ }^{1}$ Rijal S, ${ }^{1}$ Karki P' \\ 'Department of Internal Medicine, BPKIHS, Dharan, Nepal.
}

\begin{abstract}
Cough is one of the most common symptom for which patients seek medical attention from primary care physicians and pulmonologists. Although tuberculosis and other lung infections are common throughout the developing world, they are not among the most common causes of chronic cough. We report a case of a 23 years old male who presenting to the outpatient clinic with chronic cough not responding to regular and symptomatic treatment that was diagnosed to have thymoma. After all the common causes for chronic cough have been ruled out, unusual causes should also be considered in the differential diagnosis.
\end{abstract}

Key Words: Chronic cough, Thymoma, Anterior Mediastinum.

\section{INTRODUCTION}

Although cough that lasts more than eight weeks can be caused by many different diseases, most cases are attributable to only a few diagnoses. ${ }^{1}$ The clinical sequelae of mediastinal masses can range from being asymptomatic to producing symptoms of cough, chest pain and dyspnea. Tumors of the mediastinum represent a wide diversity of disease states. The location and composition of a mass is critical to narrowing the differential diagnosis. The most common causes of an anterior mediastinal mass include the following: thymoma; teratoma; thyroid disease; and lymphoma. Thymoma is the most common neoplasm of the anterior mediastinum with an incidence of 0.15 cases per 100,000 . $^{2}$

\section{CASE REPORT}

A 23 years old, male, non smoker and a health professional who presented at the adult chest clinic of B.P. Koirala Institute of Health Sciences with complaints of chronic cough for 10 years. The cough was mild, productive in nature with streaks of mucoid sputum, non foul smelling and with no diurnal or postural variation. He used to take cough suppressants and get symptomatic relief. Two months ago his symptoms aggravated and were not relieved with the cough suppressants and antibiotics. Subsequently he experienced left sided chest pain and shortness of breath on exertion which increased when lying flat. As his symptoms worsened he attended adult chest clinic at BPKIHS. General examination was essentially

Correspondence:

Dr. Krishna Kumar Agrawal

Department of Internal Medicine

BPKIHS, Dharan, Nepal.

Email: agrawalkris@gmail.com

Phone: 9803244621 
normal. On chest examination trachea was slightly deviated to the right and the chest wall bulged on the left side. Vocal fremitus was decreased in the $2^{\text {nd }}$ to $6^{\text {th }}$ left intercostal space anteriorly. Percussion was dull in the left mammary area along with decreased air entry and vocal resonance on the same side. Other system's examination revealed no abnormality. Routine blood examinations were within the normal range. Sputum examination showed gram positive cocci in pairs but culture showed no growth. An acid fast bacillus staining was negative for all samples. Radiological changes have been found (Figure 1,2).

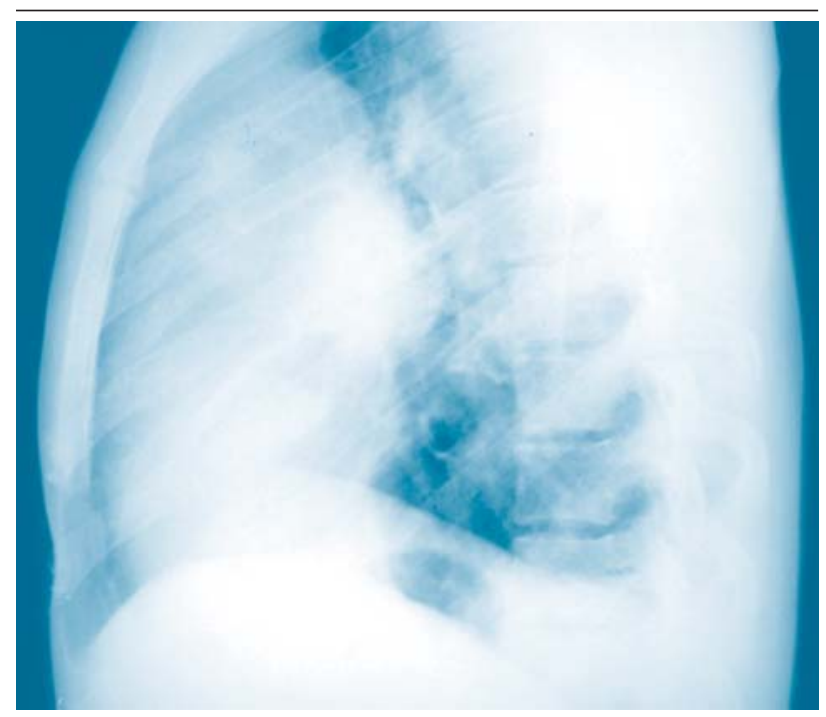

Figure 1. The enlarged mediastinal shadow with lobulated and well demarcated margins making obtuse angle with the mediastinum in the left hilar region.

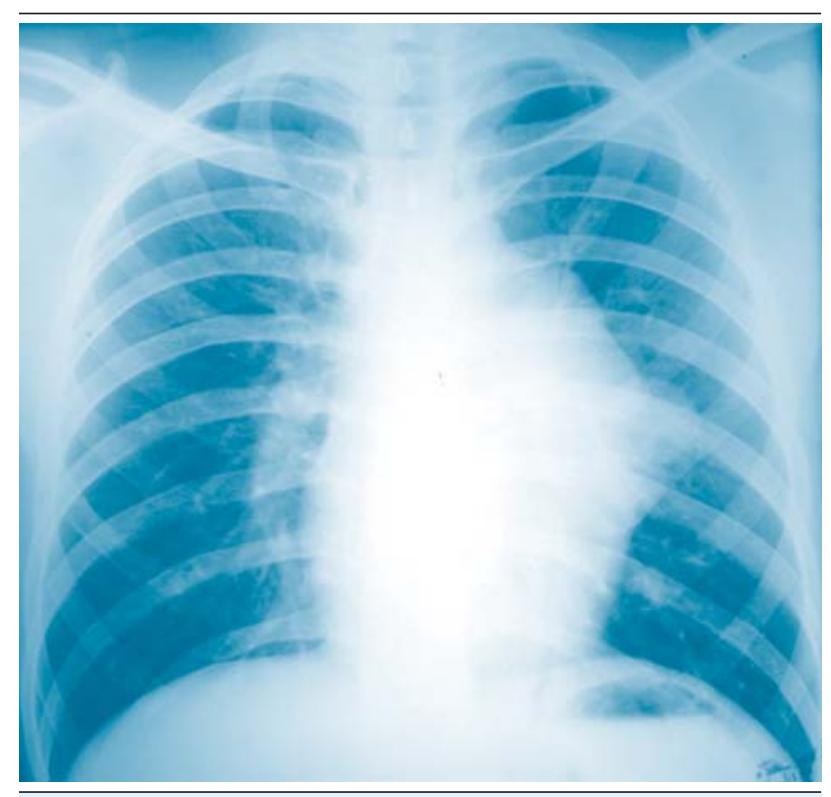

Figure 2. The lateral view of chest $x$-ray showing a homogenous shadow in the anterior mediastinum covering the whole of the anterior mediastinum.

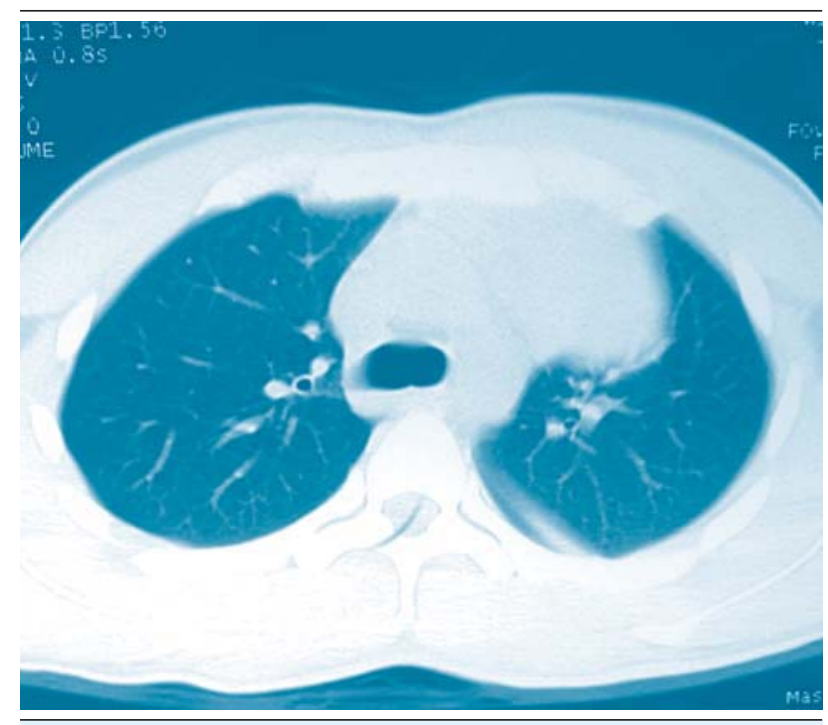

Figure 3. CECT chest at the level of T4 vertebrae.

The contract-enhanced CT scan showed a large moderately enhancing lobulated mass lesion with non enhancing areas (s/o necrosis) and calcifications within is seen in the anterior mediastinum on the left side. The lesion is extending from the level of arch of aorta to the level of left ventricle. Anteriorly and laterally the lesion is abutting the chest wall and medially abutting the pulmonary trunk, left pulmonary artery \& pericardium and compressing the left pulmonary artery with loss of fat planes at places s/o Teratoma in anterior mediastinum.

An ultrasound guided fine needle aspiration from the mass was cellular which showed cohesive tissue fragments. These cells in the fragments exhibit high nuclear cytoplasmic ratio with bland nuclear chromatin, visible nucleoli and moderate amount of cytoplasm with ill defined border. Lymphoid cells seen were intermixed within the tissue fragments. Occasional spindle cells were also seen. Mitotic figures and necrosis were not seen in smear examined. The features were suggestive of Thymoma. Patient had no evidence of Myasthenia.

\section{DISCUSSION}

Cough that lasts longer than eight weeks can be caused by many different diseases, ${ }^{3}$ most cases are attributable to only a few diagnoses. ${ }^{1}$ Most common causes of persistently troublesome chronic cough are postnasaldrip syndrome, bronchial asthma, and gastroesophageal reflux disease. ${ }^{4}$ Primary mediastinal malignancies are rare tumors. ${ }^{5}$ Thymoma is an uncommon tumor, best known for its association with the neuromuscular disorder . Thymoma is found in $15 \%$ of patients with myasthenia gravis. In our case the patient had no features suggestive of myasthenia gravis. The typical age at diagnosis of thymoma is $30-40$ years. ${ }^{2}$ Our case presented in the 
third decade. Tumors of the mediastinum represent a wide diversity of disease states.

The location and composition of a mass is critical to narrowing the differential diagnosis. The most common causes of an anterior mediastinal mass include the following: thymoma; teratoma; thyroid disease; and lymphoma. ${ }^{2}$ Thymoma is a originating from the ic epithelial cells and also known as thymic epithelial tumors (TETs). ${ }^{6}$ The most common symptoms at presentation are as follows: chronic cough $(60 \%)$; chest pain $(30 \%)$; fevers/chills (20\%); and dyspnea (16\%). Localizing symptoms are secondary to tumor invasion. Common localizing symptoms include respiratory compromise; dysphagia; paralysis of the limbs, diaphragm and vocal cords; Horner syndrome; and superior vena cava syndrome. ${ }^{2}$

Table 1. Masaoka clinical staging system for thymoma.

\begin{tabular}{llc}
\hline Stage & Degree of invasion & $\begin{array}{c}5 \text { year } \\
\text { survival rate, } \%\end{array}$ \\
\hline 1 & $\begin{array}{l}\text { complete encapsulation } \\
\text { macroscopically and no capsular } \\
\text { invasion microscopically. }\end{array}$ & $96-100$ \\
2 & $\begin{array}{l}\text { Invasion into surrounding fatty } \\
\text { tissue or mediastinal pleura }\end{array}$ \\
& $\begin{array}{l}\text { macroscopically or invasion into } \\
\text { capsule microscopically. }\end{array}$ & $86-95$ \\
3 & $\begin{array}{l}\text { Invasion into neighbouring organs } \\
\text { macroscopically }\end{array}$ & $56-69$ \\
$4 a \quad$ & $\begin{array}{l}\text { Pleural or Pericardial dissemination } \\
\text { Lymphogenous or hematogenous }\end{array}$ & $11-50$ \\
$4 b$ & \begin{tabular}{l} 
metastasis \\
\hline
\end{tabular}
\end{tabular}

The Masoka clinical staging system is based on the degree of invasion of the tumor through the capsule into the surrounding structures, which has important implications for the prognosis (Table 1). The World Health Organization devised a new classification system to group thymomas based on cytologic differences which may be helpful in determining treatment regimens and predicting survival It is (Table 2). ${ }^{2}$

Table 2. World Health Organization Classification of thymoma.

\begin{tabular}{ll}
\hline Class of Thymoma & Cytologic features \\
\hline Type A & Spindle cell, medullary \\
Type AB & Mixed \\
Type B1 & $\begin{array}{l}\text { Lymphocyte rich,lymphocytic, } \\
\text { predominantly cortical, organoid }\end{array}$ \\
Type B2 & Cortical \\
Type B3 & $\begin{array}{l}\text { Epithelial,atypical squamous, well } \\
\text { differentiated thymic Carcinoma }\end{array}$ \\
\hline
\end{tabular}

Mediastinal tumors are a rare entity but they should be an important part in assessing a case of chronic cough. The dictum of ruling out tuberculosis in cough of more than two weeks is paramount in our setup but once tuberculosis has been ruled out other causes also be looked for.

\section{REFERENCES}

1. Irwin RS, Boulet LP, Cloutier MM, Fuller R, Phillip M, Hoffstein V et al. Managing cough as a defense mechanism and as a symptom. A consensus panel report of the American College of Chest Physicians. Chest. 1998;114(Suppl):133S-181S.

2. Duwe BV, Daniel HS and Musani Ali I.Tumors of mediastinum. Chest. 2005;128:2893-9.

3. Irwin RS, Curley FJ, Grossman RF. Diagnosis and treatment of symptoms of the respiratory tract. Armonk (NY):Futura Publishing; 1997. p. 1-54.
4. Irwin RS. The Diagnosis and treatment of cough. NEJM. 2000;343(23):1715-21.

5. Dubashi B, Cyriac S, Tenali SG. Clinicopathological analysis and outcome of primary mediastinal malignancies - A report of 91 cases from a single institute. Ann Thorac Med. 2009;4:140-2.

6. Chen G. New WHO histological classification predicts prognosis of thymic epithelial tumors a clinicopathologic Study of 200 thymoma cases from china. Cancer. 2002;95(2):420-9. 